\title{
Review: Advancements and application of immunosensors in the analysis of food contaminants
}

\author{
MD. SHOFIUL AZAM ${ }^{1, \vartheta}$, MD. RAMIM TANVER RAHMAN ${ }^{1}$, ZAIXIANG LOU ${ }^{1}$, YUXIA TANG ${ }^{1}$, \\ SALEH MUHAMMED RAQIB ${ }^{2}$, JAKIA SULTANA JOTHI ${ }^{3}$ \\ ${ }^{1}$ State Key Laboratory of Food Science and Technology, School of Food Science and Technology, Jiangnan University, Wuxi214122, Jiangsu Province, \\ People's Republic of China. Tel./Fax.+86-15251526579, ”email: shofiul.sust@gmail.com \\ ${ }^{2}$ Department of Bioscience, School of Graduates, Sebelas Maret University, Surakarta 57126, Central Java, Indonesia. \\ ${ }^{3}$ Department of Food Processing \& Engineering, Chittagong Veterinary and Animal Sciences University, Khulsi- 4225, Chittagong, Bangladesh.
}

Manuscript received: 23 September 2014. Revision accepted: 6 October 2014

\begin{abstract}
Azam MS, Rahman MRT, Lou Z, Tang Y, Raqib SM, Jothi JS. 2014. Advancements and application of immunosensors in the analysis of food contaminants. Nusantara Bioscience 6: 186-195. Immunosensors are affinity ligand-based biosensor solid-state devices in which the immunochemical reaction is coupled to a transducer. The fundamental basis of all immunosensors is the specificity of the molecular recognition of antigens by antibodies to form a stable complex. This is similar to the immunoassay methodology. Immunosensors can be categorized based on the detection principle applied. The main developments are electrochemical, optical, and microgravimetric immunosensors. In contrast to immunoassay, modern transducer technology enables the label-free detection and quantification of the immune complex. The analysis of trace substances in environmental science, pharmaceutical and food industries is a challenge since many of these applications demand a continuous monitoring mode. The use of immunosensors in these applications is most appropriate. Food chemists should take advantage of immunosensors in food and clinical diagnostics. There are many recent developments in the immunosensor field which have potential impacts. The future role of this technique in intra-laboratory, as well as bedside testing, will become even more important as the food laboratory is faced with increasing pressure to contain costs. Objective of this paper is to give a general overview of the possible application of immunosensors to the food analysis field.
\end{abstract}

Keyword: Antibody, antigen, aptamers, food biosensors, immunosensor.

Abbreviation: Antibody (Ab), Antigen (Ag), Atomic Force Microscopy (AFM), Enzyme-Linked Immunosorbent Assay (ELISA), Genetic Modified Organism (GMO), Monoclonal antibody (Mab), Quartz Crystal Microbalance (QCM), Scanning Electron Microscopy (SEM), single-chain Fv fragments (scFv).

\section{INTRODUCTION}

Immunoassay techniques are based on the ability of antibodies to form complexes with the corresponding antigens (Ags). This property of highly specific molecular recognition of Ags by antibodies leads to highly selective of assays based on immune principles. The extreme affinity of antigen-antibody (Ag-Ab) interactions results in great sensitivity of immunoassay methods. Immunoassay techniques used mainly in clinical analysis and medical diagnosis. However, immunoassay applications in other areas such as environmental control, food quality control etc are expanding (Rogers 1995). The detection of biological and chemical pathogens, and other contaminants in food products plays an important role in the prevention of disease spread and infections (Borrebaeck 2000). Biosensors are currently used in food analysis in the detection of pesticide residues and there are promising faster methods compared to the chromogenic analytical tools (Jiang et al. 2008). During the last few years, a significant number of publications have dealt with nonconventional (alternative) immunoassay techniques. The development of alternative immunoassay techniques aims in most cases at improvements in performance of conventional immune analyses, by such means as decreasing analysis times, increasing assay sensitivity, and simplification and automation of assay procedures.

This review discusses principles of some alternative immunoassay techniques. Attention is focused upon electro-chemical immunoassay techniques and electrochemical immunosensors based on these techniques, because of their potential and the wealth of the recent developments.

\section{ANTIBODIES AS BIOAFFINITY INTERFACE FOR BOTH IMMUNOASSAYS AND IMMUNOSENSORS}

It should first be clarified that the specificity for the measurement of analyte(s) in all immunosensor systems, as in the case of immunoassays, is dependent on the application of binding molecules. This pivotal feature is shared by both technologies. New developments in protein engineering for immunoglobulins ( $\mathrm{Ab}$ fragments, chimeric antibodies, etc.) or in substituting antibodies by alternative binding components (e.g., aptamers) or structures (molecular imprinting) will, therefore, be applicable to either technologies, if available. In particular, the 
possibilities in $\mathrm{Ab}$ engineering will enable changes in the affinity and fine specificity of antibodies (Borrebaeck 2000; Soderlind 1999) as well as the expression of fragments as fusion proteins coupled to reporter molecules (Casadei et al 1990).

\section{Immobilization procedures for antibodies}

Antibodies have to be properly immobilized on the immunosensor surface, which is mostly part of a flowthrough cell. The optimum density and adjusted (but not random) orientation of the antibodies are of paramount importance. Due to the different types of sensing surfaces, this manipulation can have benefits, e.g., improvement of the reaction kinetic parameters), but also unfavorable effects, e.g., increased nonspecific binding, partly destroyed paratope. There are four different types of oriented coupling of antibodies: binding to Fc receptors (such as protein $\mathrm{A}$ or $\mathrm{G}$ or recombinant $\mathrm{A} / \mathrm{G}$ fusion protein) on the surface (Dubrovsky et al. 1995; Quinn et al. 1999); binding of other binding partners to structures, covalently linked to the $\mathrm{Fc}$ part of the $\mathrm{Ab}$, e.g., the biotin residue on the Fc binds to surface-coated streptavidin (Pearson et al. 1998; Schetters 1999); coupling to the solid support via an oxidized carbohydrate moiety on the $\mathrm{C}_{\mathrm{H}} 2 \mathrm{Fc}$ domain; and the binding of Fab or scFv fragments to the surface of the device via a sulfhydryl group in its $\mathrm{C}$-terminal region ( $\mathrm{Lu}$ et al. 1996; Domen et al. 1990). Numerous chemical reactions can be applied to the immobilization onto solid surfaces. Defined linkages between the antibody (or its carbohydrate moieties) and the solid phase material (silica, silanized silica, Ta- or Ti-oxides, plastics, sepharose, metal films) are being built by glutaraldehyde, carbodiimide, succinimide ester, maleinimide, periodate or galactose oxidase (EC1.1.3.9.) (Brynda et al. 1998). Moreover, photo-immobilization of antibodies using albumin, derivatives with aryldiaziridines as photolinker, is applicable (Gao et al. 1995). Physiosorption is not recommended due to the local instability of the layer caused by the mechanical stress in the flow-through cell. An exciting new method for Ab immobilization of a quartz surface of a piezoelectric sensor was presented by Nakanishi et al. (1996).

\section{Regeneration of Ab-coated sensor surfaces}

Conventional homogeneous and heterogeneous immunoassays, respectively, work discontinuously. It is highly desirable, however, that immunosensor devices, applied in food, are capable of quasi-continuous recording. The repeated use of disposable sensing elements may mimic a pseudocontinuous action, but this is not considered here. In true immunosensors, the analyter Ag interaction on the sensor-coated surface is reversible. With the given short incubation times in the flow-through device, the reaction between $\mathrm{Ag}$ and $\mathrm{Ab}$ is far off the equilibrium state. Fast reversibility and high sensitivity are mutually exclusive of each other. This was made clear by Hock in a comprehensive theoretical explanation (Winter et al. 1994). Consistently, an adequate analytical sensitivity is only warranted if antibodies with increased affinity $(1010 \mathrm{Ml}$ or at least with highly improved on-rate) are applied. The regeneration of the binding sites of the antibodies bound to the immunosensor surface needs stringent procedures. $\mathrm{Ab}$ regeneration using acidic or alkaline solutions, guanidinium chloride, or ionic strength shock is potentially harmful to the binding ability and may lead to a diminished lifetime of the immobilized antibodies and insidious drift problems. Besides this, it must be considered that with the short reaction times between the antibodies and soluble analytes in the flow-through system, the cross-reactivity of the $\mathrm{Ab}$ applied can be increased. A highly specific recognition of the antigen is a kinetic-controlled process due to the complexity of the conformational changes in the $\mathrm{Fab}$ portion of the $\mathrm{Ab}$ upon binding of the antigen.

\section{Alternative analyte-binding compounds for immunosensor applications \\ Aptamers}

Aptamers are single-stranded DNA or RNA oligonucleotide sequences with the capacity to recognize various target molecules with high affinity and specificity. These ligand-binding oligonucleotides mimic properties of antibodies in a variety of diagnostic formats. They are folded into unique overall shapes to form intricate binding furrows for the target structure (Tuerk and Gold 1990). Aptamers are identified by an in vitro selection process known as systematic evolution of ligands by exponential enrichment (SELEX) (Ansell et al. 1996; Schlehuber et al. 2000). Aptamers may have advantages over antibodies in the ease of depositing them on sensing surfaces. Moreover, due to the highly reproducible synthetic approach in any quantities.

\section{Anticalins}

Lipocalins constitute a family of proteins for storage or transport of hydrophobic and/or chemically sensitive organic compounds. The retinol-binding protein is an example in human physiology. Schlehuber et al. (2000) demonstrated that the bilin-binding protein, a member of the lipocalin family and originating from the butterfly Pieris brassicae, can be structurally reshaped in order to specifically complex potential Ags, such as digoxigenin, which was given as an example. These binding proteins share a conserved b-barrel, which is made of eight antiparallel b-strands, winding around a central core. At the wider end of the conical structure, these strands are connected in a pair wise manner by four loops that form the ligand binding site.

\section{Molecular imprinting techniques}

This is a technique that is based on the preparation of polymeric sorbents with selectivity predetermined for a particular substance, or group, or structural analogs (Berson and Yalow 1959; Price 1998). Functional and cross-linking monomers of plastic materials, such as methacrylics and styrenes, are allowed to interact with a templating ligand to create low-energy interactions. Subsequently, polymerization is induced. During this process, the molecule of interest is entrapped within the polymer either by a non covalent, self-assembling approach, or by a reversible, covalent approach. 


\section{IMMUNOASSAY AND IMMUNOSENSOR TECHNOLOGIES}

\section{Definitions \\ Immunoassays}

Immunoassays use antibodies or Ab-related reagents for the determination of sample analytes (Hage 1999; Ivnitski et al. 1999). This analytical tool has experienced an evolutionary history since 1959, when Berson and Yalow (1959) first described the radioimmunoassay (RIA) principle. In the RIA, a fixed and limited amount of antibodies is reacted with a fixed and limited amount of radiolabeled $\mathrm{Ag}$ tracer and a variable concentration of the analyte (Gosling 1990). The selectivity of the ligandbinding of antibodies allows these biomolecules to be employed in analytical methods that are highly specific even in complex biological matrices, such as blood, plasma, or urine (Ngo 2000; Sokoll and Chan 2001; Turner et al. 1999).

\section{Biosensors and immunosensors}

A biosensor is an analytical device that integrates a biological element on a solid-state surface, enabling a reversible biospecific interaction with the analyte, and a signal transducer while immune sensors are based on specific Ab-Ag interactions (Ivnitski et al. 1999; Leonard et al. 2003). The biological element is a layer of molecules qualified for biorecognition, such as enzymes, receptors, peptides, single stranded DNA, even living cells are applicable. If antibodies or $\mathrm{Ab}$ fragments are applied as biological element the device is called immunosensor. Compared to conventional analytical instruments, biosensors are characterized by an integrated structure of these two components. Many devices are connected with a flow-through cell, enabling a flow-injection analysis (FIA) mode of operation. Biosensors combine high analytical specificity with the processing power of modern electronics to achieve highly sensitive detection systems. There are two different types of biosensors: biocatalytic and bioaffinity-based biosensors (Sokoll and Chan 1999).

\section{Immunosensor principles}

The general immunosensor design is depicted in Figure 1. There are four types of immunosensor detection devices: electrochemical (potentiometric, amperometric or conductometric capacitative), optical, microgravimetric, and thermometric. The latter detection modes are neglected in this discourse due to a lack of considerable applications. All types can either be run as direct (non labeled) or as indirect (labeled) immunosensors. The direct sensors are able to detect the physical changes during the immune complex formation, whereas the latter sensors use signalgenerating labels which allow more sensitive and versatile detection modes when incorporated into the complex. There is a great variety of different labels which have been applied in indirect immunosensors. Since they are in principle the same labels as used in immunoassays, the reader is referred to relevant references, dealing with modern immunoassay technology and automation (Kricka 1998; Gajda and Hawthorn 1999; Mendoza et al. 1999).
Among the most valuable labels are enzymes such as peroxidase (EC 1.11.1.7.), glucose oxidase (EC 1.1.3.4.), alkaline phosphatase (aP), catalase (EC 1.11.1.6.) or luciferase (EC 1.13.12.7), electroactive compounds such as ferrocene or In $2 \mathrm{q}$ salts, and a series of fluorescent labels (rhodamine, fluorescein, Cy5, ruthenium diimine complexes, phosphorescent porphyrin dyes, etc.). In particular, laser-induced fluorometric resonance energy transfer between two fluorophores offers methodological advantages (Clark 1956) and can be extended to fiberoptic sensing devices (Ghindilis et al. 1998).

\section{Electrochemical immunosensors}

The majority of known immunosensor devices belong to the group of electrochemical immunosensors. Electrochemical immunosensors may possess several advantages, for example high sensitivity, low cost and portable design. The principle of their operation is based on the electrochemical detection of the labeled immunoagents or markers such as enzymes, metals ions or other electroactive compounds, thus providing an opportunity to analyze complex multicomponent mixtures for diagonizing diseases or monitoring the status of patients. In recent years the applications of single use screen-printed electrodes (SPEs), characterized by low-cost fabrication and mass production, have attracted an increasing interest for the development of immunosensors (especially enzyme immunosensors). Screen-printing (thick film) technology involves the printing of various inks onto planar ceramic or plastic supports. In Figures $2 \mathrm{~A}$ and $2 \mathrm{~B}$ are reported a scheme of an SPE.A novel analytical immunosensor array, which combines the ease of use of the spectrophotometric microplate and the high sensitivity of the electrochemical transducer, has also recently been proposed. The disposable sensor array employed is a device manufactured using the screen-printing technology and consists of a 96-well plate whose bottom has been modified with an array of 96 screen-printed sensors (Figures 2C and 2D) and operates using intermittent pulse amperometry (IPA) (Deng 2007).

\section{Potentiometric immunosensors}

The Nernst equation (Aizawa 1994) provides the fundamental principle of all potentiometric transducers. According to this equation, potential changes are logarithmically proportional to the specific ion activity. Potentiometric transducer electrodes, capable of measuring surface potential alterations at near-zero current flow, are being constructed by applying the following methodologies: (i) Trans-membrane potential. This transducer principle is based on the accumulation of a potential across a sensing membrane. Ion-selective electrodes (ISE) use ion-selective membranes which generate a charge separation between the sample and the sensor surface. Analogously, Ag or Ab immobilized on the membrane binds the corresponding compound from the solution at the solid-state surface and change the transmembrane potential. (ii) Electrode potential. This transducer is similar to the trans-membrane potential sensor. An electrode by itself, however, is the surface for the immunocomplex building, changing the electrode 
potential in relation to the concentration of the analyte. (iii) Field-effect transistor (FET). The FET is a semiconductor device used for monitoring of charges at the surface of an electrode, which have been built up on its metal gate between the so-called source and drain electrodes. The surface potential varies with the analyte concentration. The integration of an ISE with FET is realized in the ionselective field-effect transistor (ISFET). This technique can also be applied to immunosensors (Lopez et al. 1998).

\section{Amperometric immunosensors}

Amperometric immunosensors are designed to measure a current flow generated by an electrochemical reaction at constant voltage. There are only few applications available for direct sensing, since most (protein) analytes are not intrinsically able to act as redox partners in an electrochemical reaction. Therefore, electrochemically active labels (directly or as products of an enzymic reaction) are needed for the electrochemical reaction of the analyte at the sensing electrode. Oxygen and $\mathrm{H}_{2} \mathrm{O}_{2}$

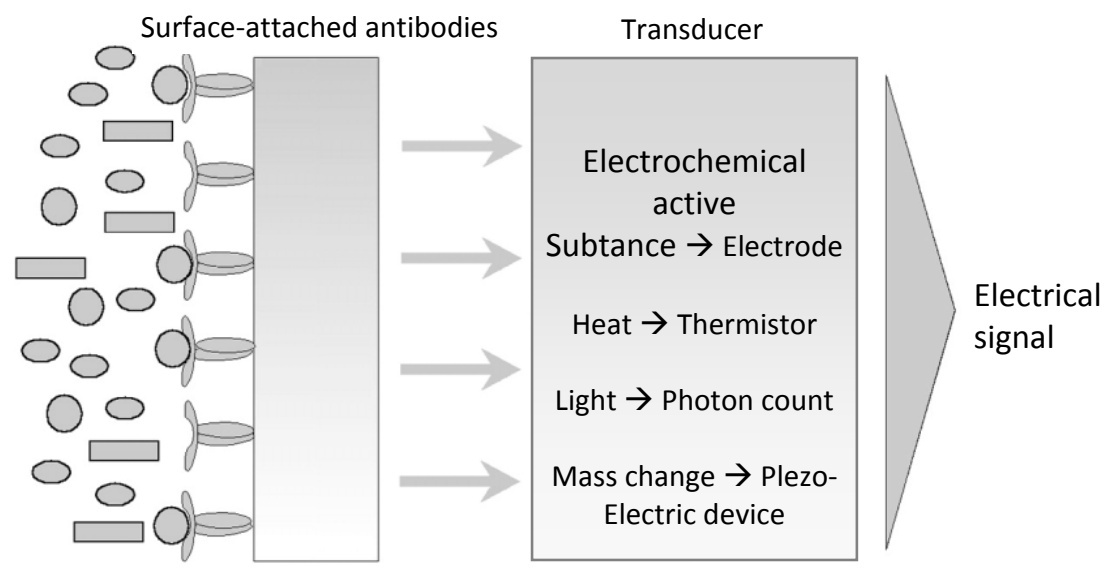

Figure 1. Scheme of the general immunosensor design depicting the intimate integration of immunological recognition at the solid-state surface and the signal transduction.


Figure 2.A. Schematic view, and B. picture of a common screen-printed electrode. C. Multichannel electrochemical immunoassays (MEI), with D. A close-up of a single well and instrumentation reader. 
electrodes are the most popular. First described by Clark (1956), an oxygen electrode consists of an electrolytebearing chamber with a sensing Pt cathode, polarized at $0.7 \mathrm{~V}$, and an $\mathrm{Ag} / \mathrm{AgCl}$ reference electrode. The chamber is gas-permeable, covered by an $\mathrm{O}_{2}$ pervious membrane. The probable cathodic reactions are as follows:

$$
\begin{gathered}
\mathrm{O}_{2}+2 \mathrm{H}_{2} \mathrm{O}+2 \mathrm{e}^{-} \rightarrow \mathrm{H}_{2} \mathrm{O}_{2}+2 \mathrm{OH}, \\
\mathrm{H}_{2} \mathrm{O}_{2}+2 \mathrm{e}^{-} \rightarrow 2 \mathrm{OH} .
\end{gathered}
$$

The anodal reaction: $4 \mathrm{Ag}+4 \mathrm{Cl} \rightarrow 4 \mathrm{AgCl}+4 \mathrm{e}^{-}$completes the electrical circuit. There is a series of enzymes with high catalytic reaction rates $\left(<10^{3} \mathrm{~s}^{-1}\right)$ in use for substrate transformation in amperometric systems, as reviewed by Ghindilis et al. (1998). In general, oxidizing rather than reducing potentials are applied.

Besides oxygen, generated by catalase from $\mathrm{H}_{2} \mathrm{O}_{2}$ there are other amperometrically detectable compounds, such as ferrocene derivatives or $\operatorname{In}^{2+}$ salts (Yang et al. 2015). A novel approach is the use of the redox polymer (PVP-Os (bipyridylCl), which is co-immobilized with specific antibodies (Gizeli and Lowe 1996). Additionally, there are examples for enzymes with electrochemically active products $(\mathrm{aP})$, for example, catalyzes the hydrolysis of phenyl phosphate or $p$-aminophenylphosphate (4-APP) compounds, which result in electrochemically active phenol or $p$-aminophenol (Morgan et al. 1996). Furthermore, enzymes, such as horseradish peroxidase (HRP Glucose oxidase, glucose-6-phosphate dehydrogenase (EC 1.1.1.49); with subsequent amperometrical oxidation of NADH. and others, have also been successfully applied as labels (Aizawa 1994).

\section{Conductometric and capacitive immunosensors}

These immunosensor transducers measure the alteration of the electrical conductivity in a solution at constant voltage, caused by biochemical (enzymatic) reactions which specifically generate or consume ions. The capacitance changes are measured using an electrochemical system, in which the bioactive element is immobilized onto a pair of noble metal (mostly, Au or Pt) electrodes. There are only few clinical applications available, as the high ionic strength of biological matrices makes it difficult to record the relatively small net conductivity changes caused by the signaling reaction (Pearson et al. 2000).To circumvent this problem, recently, an ion-channel conductance immunosensor, mimicking biological sensory functions, was described w68x. The basis of this technique is the fact that the conductance of a population of molecular ion channels, built of tethered gramicidin A and aligned across a lipid bilayer membrane, is changed by the $\mathrm{Ab}-\mathrm{Ag}$ binding event. Different applications using various antibodies, linked to the ion-channel complex, are given. Another approach is the measurement of changes of the surface conductivity. Ekins (1999) developed a conductometric immunosensor for the determination of methamphetamine (MA) in urine. Anti-MA antibodies were immobilized onto the surface of a pair of platinum electrodes. The immunocomplex formation caused a decrease in the conductivity between the electrodes.

\section{Optical sensors}

Optical immunosensors are most popular for bioanalysis and are today's largest group of transducers. This is due to the advantages of applying visible radiation compared to other transducer techniques. Additional benefits are the nondestructive operation mode and the rapid signal generation and reading. In particular, the introduction of fiber bundle optics (Aoptodes B) as optical waveguides and sophisticated optoelectronics offers increased versatility of these analytical devices for clinical applications (Kricka 1997; Ekins et al. 1998; Ekins and Chu 1999; Wang et al. 2000). Changes in adsorption, fluorescence, luminescence, scatter or refractive index (RI) occur when light is reflected at sensing surfaces. This information is the physical basis for optical sensor techniques. Usually, applied detectors are photodiodes or photomultipliers. There are numerous applications of either direct label-free optical detection of the immunological reaction, of labeled immunospecies, or of the products. But bio and chemiluminescence species are also possible.

The common principle of the following analytical devices (total internal reflection spectroscopy; tirs) is that in an optical sensor with two materials with different refractive indices RI, total internal reflection occurs at a certain angle of the light beam being directed through the layer with the higher RI towards the sensing interface. By this, an evanescence wave is generated in the material with the lower RI. This wave, being an electrical vector of the wavelength of the incident light beam, penetrates further into the medium with exponentially attenuated amplitude. Biomolecules attached in that portion of the medium will interact inevitably with the evanescent wave and, therefore, lead to a distinctive diminution of the reflected light. The resolution is directly proportional to the length of interaction (Schwesinger et al. 2000).

\section{NEW TECHNOLOGIES}

\section{Microarrays}

Today, there is great interest in multiplexed, highthroughput assays, not only for clinical applications, but also, for drug discovery (Figure 3). The microarray technique was first described by Cook et al. (1997) and Felder and Kost (1998) for an Ab microspot array. This type of microarray has to be distinguished from the DNA chip technology, which is based on nucleic-acid recognition on a surface-immobilized template. DNA biosensor arrays are of considerable recent interest due to their promise for obtaining sequence-specific information Turner (1997). They are being rapidly developed commercially towards the goal of quick, simple and precise testing for susceptibility to genetic diseases. 


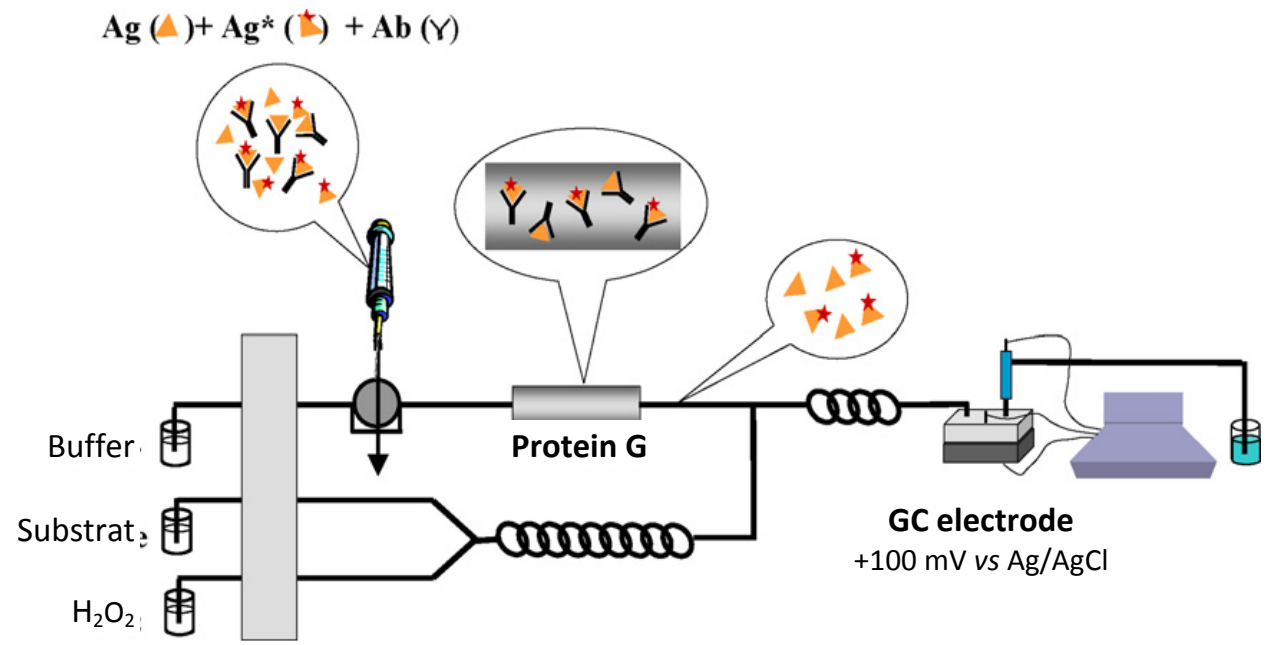

Figure 3. Flow-injection immunoassay (FI-IA) system based on amperometric detection of peroxidase enzyme $(\mathrm{HRP})$. Ag = antigen; Ag* antigen labelled with HRP; Ab= primary antibody. Reproduced with permission from Felder and Kost (1998).

\section{Atomic force microscopy}

The new techniques of atomic force microscopy (AFM) and optical trapping (optical tweezers) allow the location of individual atoms or molecules on solid-state surfaces. They are exceptional tools for the characterization of the atomic binding forces of ligand-receptor interactions (Song et al. 1994). In the AFM, a solid-state surface of interest is moved past an extremely small tip, attached to a flexible cantilever. When the tip is coated with specific molecules, the deflection of the cantilever caused by the rises and falls of the tip in response to the topology and specific interaction of the surface is registered and provides the direct molecular recognition of the binding partner on the solid-state surface. Schwesinger et al. (2000) were able to detect the unbinding forces of single Ag-Ab-complexes and to correlate them with their respective thermal dissociation constants.

\section{Nanotechnology}

Advancement in nanotechnology will help for a further development of immunosensors w146x, particularly in proteomics and cellomics. Optical fiber based nanosensors depend on the construction of nanometer-sized optical fibers. There are two different techniques already available to produce fibers' tips approximately $50 \mathrm{~nm}$ in diameter: a $\mathrm{CO}_{2}$ laser based micropipet-puller or the chemical-etching technique with hydrofluoric acid w146x. Miniaturization will allow the integration of all steps of the analytical process into single-sensor devices (lab-on-a-chip), which will be partly disposable. In particular, the fluidics parts of the sensor will benefit from this new technology and allow a reduction of sample volume ${ }^{-1} \mathrm{~mL}$. However, pumps, valves, and electronic control circuitry are also probable building parts of a miniaturized and integrated sensor (Conneely et al. 2007). Thus, cheap and even implantable immunosensors (Ammida et al. 2004a; Zacco et al. 2007) will be available and possible clinical applications will be expanded considerably.

\section{APPLICATIONS IN FOOD ANALYSIS}

\section{Veterinary drugs residues}

In modern livestock production, veterinary drugs and anabolic steroids (endogenous or synthetic hormones) are being used on a large scale. Incorrect or unauthorized use of these compounds may leave residues in edible tissues, thus causing toxic effects for consumers. In order to protect public health, maximum residue limits (MRLs) of veterinary medical products in foodstuffs of animal origin (liver, milk, egg, kidney, muscle, fat, etc.) have been established according to European Union regulation (2377/90/CEE). For natural steroid hormones (estradiol, progesterone and testosterone) action limits (to discriminate between the endogenous level and illegal animal administration) have been set for biological fluids such as blood, urine and serum (Chemburu et al. 2005).

\section{Anabolic steroids}

Concerns over the use of steroid hormones as growth promoters, have prompted the EU to prohibit their use in food producing animals. Subsequently, rigorous screening procedures have been implemented in all member states to detect the illegal administration of such compounds. Indirect competitive electrochemical immunoassays for the detection of testosterone19-nortestosterone and methyltestosterone in bovine urine were developed by Micheli et al. (2004) and Compliance Programme (2001) using conjugated testosterone-BSA immobilized onto disposable screen printed electrodes. Undiluted blank bovine urine was tested and a strong matrix effect was observed; for this reason a dilution step (1: 20 with buffer) was used to minimize this effect. The authors claim a satisfactory precision (repeatability and reproducibility), accuracy and stability. Only the immunosensor for the detection of testosterone was employed for real sample analysis on urine samples from heifers that have been 
treated at various time points with testosterone. The results obtained, even if in good agreement with a typical metabolic profile of testosterone in bovine urine, were not confirmed with a reference method.

\section{Antibiotic}

A disposable electrochemical indirect competitive assay for the detection of two macrolides (erythromycin and tylosin) in bovine muscle was recently developed using an SPE. The antibiotics were extracted from $2 \mathrm{~g}$ of homogenized tissue using $10 \mathrm{~mL}$ of $20 \%(\mathrm{v} / \mathrm{v})$ methanol in PBS by stirring for $15 \mathrm{~min}$. After centrifugation and filtration $1 \mathrm{~mL}$ of the filtrate was used for the detection of tylosin, while another aliquot was diluted in PBS (1/9: v/v) for the detection of erythromycin. To evaluate the matrix effect, calibration curves, obtained using blank meat samples spiked, after extraction, with known amounts of macrolides, were generated. Finally, blank samples spiked with mixtures of the macrolide antibiotics (at concentrations of $0.5 \times$ MRL, MRL, $2 \times$ MRL) and real samples were analyzed. The immunosensor system showed good precision and accuracy and the results obtained on real samples were confirmed by micro-LC-MS/MS showing promising features of the developed sensors. An interesting electrochemical magneto-immunosensor for the detection of sulfonamide antibiotics in milk has been presented by Zacco et al. (2006). Class-specific antisulfonamide antibodies were covalently bound on to sylactivated magnetic beads.

\section{Pathogenic bacteria}

Although in these last 5 years several electrochemical immunosensors for the detection of pathogenic bacteria have been developed, their application to food analysis is very poor. Even when the experimentation in food is carried out it does not always demonstrate in a satisfactory way the effective applicability of this kind of immunosensors in food analysis. Piermarini et al. (2007a) have developed a flow through amperometric immunoassay system utilizing highly-dispersed carbon particles as immobilization support of $\mathrm{Ag}$ specific unlabeled antibodies. A sandwich immunoassay was employed with all steps performed at a fixed flow rate.

\section{Toxins}

\section{Domoic acid}

Domoic acid (DA), a neuroexcitatory toxin from marine diatoms, which is found in sea products (especially in filter-feeding mollusks such as clams, oysters and mussels), is the causative agent for amnesic shellfish poisoning (ASP). The presence of DA-producing algal blooms throughout the world has raised concerns with fishery managers and thus detection of DA in shellfish has become essential. An electrochemical indirect competitive immunoassay for a rapid screening of DA was recently proposed (Ammida et al. 2006) based on the use of a SPE. After the characterization of the proposed system with standard solutions in buffer, the suitability of the assay for DA quantification in mussels was evaluated. Samples were spiked with DA before and after matrix effect, respectively.
After treatment of "blank" mussels, the extract was fortified with a known amount of DA and analyzed. Using a 1: $250(\mathrm{v} / \mathrm{v})$ dilution in PBS-M (phosphate saline buffer $\mathrm{pH} 7.4+\mathrm{CH}_{3} \mathrm{OH} 10 \%$ ) to minimize the matrix effect the authors claim a detection limit of $20 \mathrm{ngg}^{-1}$ of DA in mussel tissue which represents the maximum acceptable limit defined by the Food and Drug Administration (Piermarini et al. 2007a).

\section{Mycotoxins}

Mycotoxins are defined as "fungal metabolites which, when ingested, inhaled or adsorbed through the skin cause lowered performance, sickness or death in man or animals, including birds". The most important mycotoxins are the aflatoxins (AFs) and ochratoxin A (OTA) that are produced as secondary metabolites by the fungi Aspergillus and Penicillium and are known to be carcinogenic, mutagenic, teratogenic and immunosuppressive. When aflatoxin B1 (AFB1) is ingested by cows, it is transformed into its hydroxylated product, aflatoxin M1 (AFM1), which is then secreted in the milk. Unfortunately, AFM1 is relatively stable during milk pasteurization and storage as well as during the preparation of various dairy products (Micheli et al. 2005; Ammida et al. 2006). Analytical methodology must allow the determination of aflatoxins at least below the specific regulatory levels. In fact, the European Committee Regulations (ECR) has established the maximum acceptable level of AFB1 in cereals, peanuts and dried fruits for direct human consumption: $4 n g g-1$ for total aflatoxins (AFB1, AFG1, AFB2, and AFG2) and 2ngg for AFB1 alone. The current maximum level for AFM1 in milk is $0.05 \mathrm{ngmL}^{-1}$, while for OTA is $3 \mathrm{ngkg}^{-1}$ in all cereal products intended for direct human consumption (Piermarini et al. 2007)

\section{Aflatoxins}

Responding to the need to achieve high sensitivity and move to the use of disposable probes, several electrochemical immunosensors have recently been reported in literature for the detection of AFB1 in corn and barley (Ammida et al. 2006; Pierarini et al. 2007) and AFM1 in milk (AOAC 2004). In particular, for AFB1 determination, an indirect competitive electrochemical immunoassay has been developed using disposable screenprinted carbon electrodes. The specificity of the assay was assessed by studying the cross-reactivity of the MAb towards other aflatoxins. The results indicated that the $\mathrm{MAb}$ could readily distinguish AFB1 from other toxins, with the exception of AFG1. The proposed system showed a low matrix effect for barley and good recovery when analyzing spiked samples that were treated with an easy procedure: extraction of the analyte with $85 \%$ methanol: 15\% PBS, then centrifugation and dilution 1: $1(\mathrm{v} / \mathrm{v})$ with phosphate buffer. The results obtained were confirmed by HPLC coupled with fluorescence detection. The stability of the modified sensor, up to the blocking step, was also evaluated so as to have a strip ready to use directly in the competition step (Volpe et al. 2006). Recently Piermarini et al. (2007b) realized an improvement over the previously described immunoprobes for AFB1 determination in corn 
using an electrochemical immunoplate with multichannel read-out. An negligible matrix effect and good recoveries were obtained for spiked corn samples, demonstrating the suitability of the proposed assay for accurate determination of AFB1 in corn samples; however, considering the sample treatment, the method exhibited a detection limit too close to the law limit of AFB1 in corn $\left(2 \mathrm{ngkg}^{-1}\right)$. Another disposable electrochemical immunosensors has been proposed by Micheli et al. $(2004,2005)$ for the detection of AFM1 in milk (EC 1993).

\section{Ochratoxin A.}

A direct competitive immunoassay based on single disposable screen-printed electrodes has been developed for quantitative determination of ochratoxin A (OTA) in wheat (Zacco et al. 2006).A one-step procedure of extraction of OTA from wheat was used with aqueous acetonitrile $\left(\mathrm{ACN}: \mathrm{H}_{2} \mathrm{O}, 6: 4(\mathrm{v} / \mathrm{v})\right)$ solution and after filtration the extract was used directly for the analysis. A good correlation was found by comparative analysis of naturally contaminated wheat samples using the proposed immunosensor and the HPLC/immunoaffinity clean up method (Lillie et al. 2001) for determination of OTA in cereals.

\section{Detection of genetically modified organisms GMO}

Progress in genetic engineering technology has enabled the introduction and expression of novel genes in crop plants in order to produce agronomically useful traits such as insect and disease resistance. In the contest of this development, three transgenic Lepidoptera-resistant maize lines (Bt-11, MON-810, Bt-176), commonly referred to as Bt-maize, express the genes for the Bacillus thuringiensis toxic proteins Cry $1 \mathrm{Ab}(\mathrm{Bt}-11, \mathrm{MON}-810)$ and Cry $1 \mathrm{Ac}$ (Bt-176). In the EU, foods containing ingredients with a content of GMOs $>0.9 \%$ (for each ingredient) must be labeled. To enforce these regulations, reliable and fast methods for the detection and quantification of GMOs present in food products are needed. An immunomagnetic electrochemical sensor (IMES) for detection of Bt-Cry $1 \mathrm{Ab} / \mathrm{Cry} 1 \mathrm{Ac}$ proteins in genetically modified corn samples has been recently developed (Noh et al. 2006) The IMES is based on the use of magnetic beads as support for the immunological chain following a sandwich format At the end of all the immunological reactions, the immunobeads were localized onto the surface of a magnetized screen printed electrode and differential pulse voltammetry (DPV) was used for measurement. The current response was found to be directly proportional to the concentration of Cry $1 \mathrm{Ab}$ and CrylAc proteins. The scheme of this system is reported in Figure 4. This method was applied to corn samples treated with an appropriate extraction buffer. After centrifugation the supernatant was used for the IMES test. Certified reference materials (CRMs), having different mass fractions $(0.5,1,2,5 \%)$ in the dried powder prepared from genetically modified (MON 810) maize, were treated and analyzed multiple times using Cry $1 \mathrm{Ab}$ protein as calibrator in order to assess, under these experimental conditions, the correspondence between the percentage of genetically modified material and the concentration of

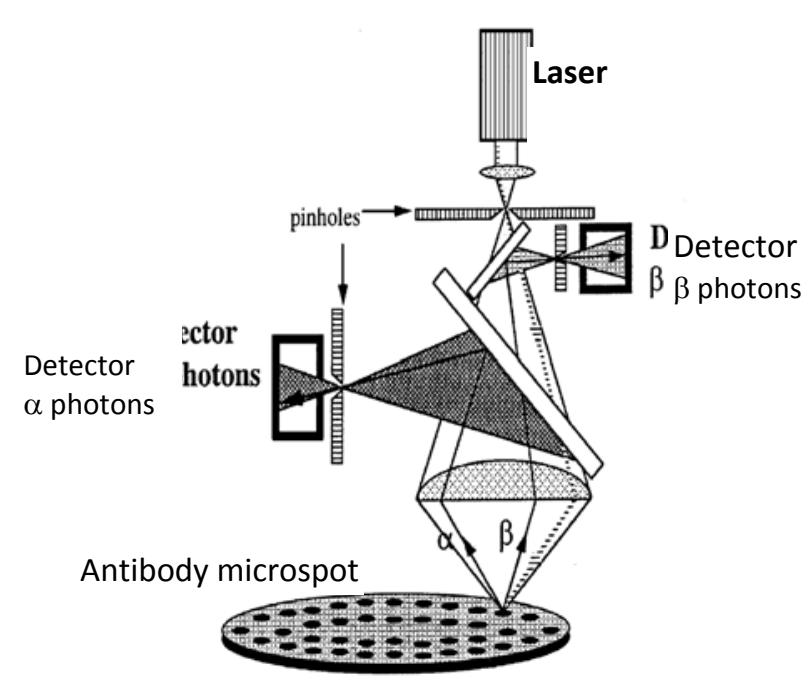

Figure 4. Microspotmultianalyte Ab array (after Rogers 1995, reproduced with permission).

CrylAb protein $\left(\mathrm{ngg}^{-1}\right)$. Once obtained, this linear correlation curve was used for all the successive GMO measurements. The performances of the immunomagnetic electrochemical sensor, in terms of detection limit and total analysis time, are comparable to those of commercially available spectrophotometric kits and thus the proposed method represents a new approach for GMO analysis.

\section{Polychlorinated biphenyls (PCBS)}

Polychlorinated biphenyls (PCBs) are ubiquitous pollutants widely diffused in the environment. Their residues have been found in air, water, milk, human and animal adipose tissue. A simple protocol for analyzing PCBs in real samples (Ammida et al. 2004b) has been developed using SPEs and a direct competition assay. With this method, araclor mixture (1242 and 1248) was determined in different matrixes including sheep's milk, bovine adipose tissue, and bovine muscle. Results obtained were compared with the results accredited from ISO 17025 methods for PCB detection (high-resolution gas chromatography and a low-resolution mass spectrometer (HRGC-LRMS) as confirmatory analysis. The extraction procedure used was in accordance with the criteria proposed by the European Directive (Morita et al. 2002) and was based on extraction with petroleum ether, evaporation under nitrogen stream and purification using alumina glass column. The minimum matrix effect observed indicates that the response of the immunosensor was only weakly influenced by the type of the sample. For this reason, normalization of the data was possible obtaining a wide applicability of the immunosensor to different typologies of food samples. This broad applicability, coupled with the high sensitivity, may lead to the use of this system as a preliminary indicator before using the HRGC/LRMS analysis in the food laboratory. 


\section{Pesticides residues}

\section{2, 4-Dichlorophenoxyacetic acid}

Dichlorophenoxyacetic acid (2,4-D) is one of the most used herbicides in agriculture, and the highest permissible concentration of this herbicide in drinking water was set by the European Union $0.1 \mathrm{ngmL}^{-1}$. Charles et al. (1995) proposed an array immunosensor (MED) for simultaneous analysis of several water samples in order to monitor for 2 , 4-D contamination. A direct competitive immunoassay was carried out in an ELISA microplate, while the enzymatic product was transferred onto another plate and determined amperometrically by the use of pre-equilibrated eightchannel electrodes. The repeatability of individual electrodes was satisfactory, and homogeneity of MED was greatly improved by tuning the electrodes with their corresponding calibration factors.

\section{Atrazine}

Atrazine has been identified as one of the herbicides that are persistent in groundwater and surface waters because of its polarity. Food and environmental regulatory agencies have established a control program in order to prevent this pollutant from entering the food supply. The European Community has thus established a maximum residue limit (MRL) of $0.1 \mu \mathrm{gmL}^{-1}$ for atrazine in potable water and fruit juice. A novel electrochemical immunosensor for the detection of atrazine residues in liquid samples (such as orange juice) has been proposed and realized by Turner (1997). A graphite-epoxy composite transducer was bulk modified with universal affinity biomolecules, such as avidin (Av-GEB) and Protein A (ProtA-GEB). Using ProtA-GEB in a direct competitive immunological electrochemical assay an excellent linear range, a low detection limit and good sensitivity were achieved with orange juice samples using atrazine-HRP tracer as enzymatic label. Because of the simplicity of the immunochemical procedure presented, this strategy seems to be well-suited for fast semiquantitative and quantitative on-site analysis of the presence of atrazine (or atrazine immunoreactive herbicide) in real samples.

\section{FUTURE DIRECTIONS}

This review has highlighted the basic mechanism of immunosensors and its applications in the food contaminant analysis. Immunosensors based on $\mathrm{Ab}-\mathrm{Ag}$ complexation are strong candidates for screening pesticide residues and they become more and more relevant inenvironmental and food analysis. Compared to chromatography and other methods, immunosensors are very selective and sensitive. They can be carried out for use in the field. They can work with complete automation and give the result safer a short period of time. Despite the promise of immunosensors, they do have certain limitations. For example, few immunosensors are commercially available at the present time and are yet to be established as research or routine tools, due to a lack of validated protocols for a wide range of sample matrices. In conjunction with electrochemical detection, these systems will offer sensitive and selective analyses that are faster, simpler, and more economical.

Although immunoassay techniques emerged over two decades ago, there are still vigorous research efforts and tremendous progress in the development of electrochemical immunoassays and immunosensors. An extraordinary feature of these immunosystems is their specificity. There are continuing studies on examining various strategies that will aid in aligning antibodies on a solid phase in an optimal direction with minimal steric hindrance. Development in this area will undoubtedly further enhance the degree of sensitivity achievable in analyses involving immunoassays and immunosensors. The application of electrochemical impedance spectroscopy has started to facilitate a label-free scheme, and this is definitely an attractive, simpler alternative to others involving the required sensitivity and dynamic range obtainable in amperometric detection. With the future direction in the manufacture of miniaturized immunoassay devices, this will open up opportunities for developing hand-held tools for instant on-site food analysis, pharmaceutical and clinical diagnosis, particularly in response to gradual shift towards home-based diagnosis. New immunosensor technologies are anticipated in the near future in response to these exciting opportunities.

\section{REFERENCES}

Aizawa M. 1994. Immunosensors for clinical analysis. Adv Clin Chem 31: $247-275$.

Ammida NH, Volpe G, Draisci R, delli Quadri F, Palleschi L, Palleschi G. $2004 \mathrm{~b}$. Analysis of erythromycin and tylosin in bovine muscle using disposable screen printed electrodes. Analyst 129 (1): 15-19.

Ammida NHS, Micheli L, Palleschi G. 2004a. Electrochemical immunosensor for determination of aflatoxin B1 in barley. Analy Chim Acta 50: 159-164.

Ammida NHS, Micheli L,Piermarini S, Palleschi G. 2006. Detection of Aflatoxin B1 in Barley: Comparative study of immunosensor and HPLC. Analyt Lett 39: 1559-1572.

Ansell RJ, Ramstrom O, Mosbach K. 1996. Towards artificial antibodies prepared by molecular imprinting. Clin Chem 42: 1506-1512.

AOAC. 2004. International Performance Tested Methods. Toxin Tests Kits. www.aoac.org.

Berson SA, Yalow RS. 1959. Assay of plasma insulin in human subjects by immunological methods. Nature 184: 1648-1649.

Borrebaeck CAK. 2000. Antibodies in diagnostics-from immunoassays to protein chips. Immunol Tod 21: 379-381.

Brynda E, Houska M, Kvor J, Ramsden JJ. 1998. Immobilisation of multilayer bioreceptor assemblies on solid substrates. Biosens Bioelect 13: 165-172.

Casadei J, Powell MJ, Kenten JH. 1990. Expression and secretion of aequorin as a chimeric antibody by means of a mammalian expression vector. Proc Natl Acad Sci USA 87: 2047-2051.

Charles PT, Conrad DW, Jacobs MS, Bart JC, Kusterbeck AW. 1995. Synthesis of a fluorescent analog of polychlorinated biphenyls for use in a continuous flow immunosensor assay. Bioconjug Chem 6 (6): 691-694.

Chemburu S, Wilkins E, Hamid IA. 2005. Detection of Pathogenic bacteria in food samples using highly dispersed carbon particles. Biosens Bioelect 21: 491-499.

Clark LC. 1956. US Patent a2,913,386.

Commission Regulation no. 472/2002 of 12 March 2002 and no. 123/2005 of 26 January 2005.

Compliance Programme. 2001. 7303.842. Guidance Levels, Table 3, p. 248, http: //www.fda.org

Conneely G, Aherne M, Lu H, Guilbault GG. 2007.Development of an immunosensor for the detection of testosterone in bovine urine. Anal Chim Acta 583 (1): 153-160. 
Cook CJ. 1997. Real-time measurements of corticosteroids in conscious animals using an Ab-based electrode. Nat Biotechnol 15: 467-471.

Deng AN, Yang H. 2007.A multichannel electrochemical detector coupled with an ELISA microtiter plate for the immunoassay of 2,4dichlorophenoxyacetic acid. Sens Actuat B: Chem 124 (1): 202-208.

Domen PL, Nevens JR, Mallia AK, Hermanson GT, Klenk DC. 1990. Site-directed immobilization of proteins. J Chromatogr 510: 293-302.

Dubrovsky T, Tronin A, Dubrovskaya S, Vakula S, Nicolini C. 1995. Immunological activity of $\mathrm{Ig} \mathrm{G}$ Langmuir films oriented y protein $\mathrm{A}$ sublayer. Sens Actuat B: Chem 23: 1-7.

EC. 1993. EC 93/256: Commission decision of 14 April 1993. Official J Eur Comm 1993, L118.

Ekins RP, Chu FW. 1999. Microarrays: their origins and applications Tibtech 17: 217-218.

Ekins RP. 1998. Ligand assays: from electrophoresis to miniaturized microarrays. Clin Chem 44: 2015-2030.

Felder RA, Kost GJ. 1998.Automation: Part 1. Modular stepwise automation and the future of diagnostic testing. MLO Med Lab Obs 30 (4): $22-27$.

Gajda A, Hawthorn M. 1999. Laboratory technology. Simultaneous multiple analyte testing: the next 'revolution' in lab testing? Adv Lab 8: $69-70$

Gao H, Sanger M, Luginbuhl R, Sigrist H. 1995. Immunosensing with photoimmobilizedimmunoreagents on planar wave guides. Biosens Bioelect 10: 317-328.

Ghindilis AL, Atanasov P, Wilkins M, Wilkins E. 1998. Immunosensors electrochemical sensing and other engineering approaches. Biosens Bioelect 13: 113-131.

Gizeli E, Lowe CR. 1996. Immunosensors. Curr Op Biotechnol 7: 66-71.

Gosling JP. 1990. A decade of development in immunoassay methodology. Clin Chem 36: 1408-1427.

Hage DS. 1999. Immunoassays. Anal Chem 71: 294R-304R.

Ivnitski D, Abdel-Hamid I, Atanasov P, Wilkins E. 1999. Biosensors for detection of pathogenic bacteria. Biosens Bioelect 14: 599.

Jiang $\mathrm{X}$, Dongyang Li, Xia Xu, Yibin Ying, Yanbin Li, Zunzhong Ye, Jianping W. 2008. Immunosensors for detection of pesticide residues. Biosens Bioelect 23 (11) ; 1577

Kricka LJ. 1997. Optical tweezers and immunoassay. Clin Chem 43: 251253.

Kricka LJ. 1998. Miniaturization of analytical systems. Clin Chem 44: 2008-2014

Leonard P, Hearty S, Brennan J, Dunne L, Quinn J, Chakraborty T, Otron R. 2003. 21 Advances in biosensors for detection of pathogens in food and water. Enzyme Microbial Technol 32: 3.

Li DJ, Sokoll LJ, Chan DW. 1998. Automated chemiluminescent immunoassay analyzers. J Clin Ligand Assay 21: 377-385.

Lillie G, Payne P, Vadgama P. 2001. Electrochemical impedance spectroscopy as a platform for reagentless bioaffinity sensing. Sens Actuat B: Chem 78: 249-256.

Lopez MA, Ortega F, Dominguez E, Katakis I. 1998. Electrochemical immunosensor for the detection of atrazine. J Mol Recognit 11: 178181.

Lu B, Smyth MR, O'Kennedy R. 1996. Oriented immobilization of antibodies and its applications in immunoassays and immunosensors. Analyst 121: 29R-32R.

Micheli L, Grecco R, Badea M, Moscone D, Palleschi G. 2005. An electrochemical immunosensor for aflatoxin M1 determination in milk using screen -printed electrodes. Biosens Bioelect 21 (4): 588596.

Micheli L, Radoi A, Guarrina R, Massaud R, Bala C, Moscone D, Palleschi G. 2004. Disposable immunosensor for the determination of domoic acid in shellfish. Biosens Bioelect 20 (2): 190-196.

Morgan CL, Newman DJ, Price CP. 1996. Immunosensors: technology and opportunities in laboratory medicine. Clin Chem 42: 193-209.

Morita Y, Murakami Y, Yokoyama K, Tamiya E 2002. In: Marten MR, Park TH, Nagmune T (eds) Synthesis and Analysis of Peptide Ligand for Biosensor Application using Combinatorial Chemistry. ACS Symposium, New York.

Nakanishi K, Muguruma H, Karube I. 1996. A novel method of immobilizing antibodies on a quartz crystal microbalance using plasma-polymerized films for immuno-sensors. Anal Chem 68: 16951700 .
Ngo TT. 2000. Developments in immunoassay technology. Methods 22: $1-3$.

Noh MFM, Tothill IE. 2006. Development and characterisation of disposable gold electrodes, and their use for lead (II) analysis. Anal Bioanal Chem 386: 2095-2210.

Pearson JE, Gill A, Vadgama P. 2000. Analytical aspects of biosensors. Ann Clin Biochem 37: 119-145.

Pearson JE, Kane JW, Petraki-Kallioti I, Gill A, Vadgama P. 1998. Surface plasm on resonance: a study of the effect of biotinylation on the selection of antibodies for use in immunoassays. J Immunol Methods 221: 87-94.

Piermarini S, Volpe G, Ricci F, Micheli L, Moscone D, Palleschi G, Führer M, Krska R, Baumgartner S. 2007a. Rapid screening electrochemical methods for aflatoxin B1 and type-A trichothecenes: A preliminary study. Anal Lett 40 (7): 1333-1346

Piermarini S, Micheli L'Ammida NHS, Palleschi G, Moscone D. 2007b. Electrochemical immunosensor array using a 96-well screen-printed microplate for aflatoxin $\mathrm{B}_{1}$ detection. Biosens Bioelect 22 (7): 14341440

Price CP. 1998. The evolution of immunoassay as seen through the journal Clinical Chemistry. Clin Chem 44: 2071-2074.

Quinn J, Patel P, Fitzpatrick. 1999. The use of regenerable, affinity ligandbased surfaces for immunosensor applications. Biosens Bioelect 14: 587-595.

Rogers KR. 1995. Biosensors for environmental applications. Biosens Bioelect 10: 533-541.

Schetters H. 1999. Avidin and streptavidin in clinical diagnostics. Biomol Eng16: 73-78.

Schlehuber S, Beste G, Skerra A. 2000. A novel type of receptorprotein, based on the lipocalin scaffold, with specificity for digoxigenin. J Mol Biol 297: 1105-1120.

Schwesinger F, Ros R, Strunz. 2000. Unbinding forces of single Ab-Ag complexes correlate with their thermal dissociation rates. Proc Natl Acad Sci 97: 9972-9977.

Soderlind E, Ohlin M, Carlsson R. 1999. Complementarity-determining region CDR. implantation: a theme of recombination. Immunotechnology 4: 279-85.

Sokoll LJ, Chan DW. 1999. Clinical analyzers.Immunoassay. Anal Chem 71: 356-362.

Sokoll LJ, Chan DW. 2001. Choosing an automated immunoassay system. In: Wild D (ed). The immunoassay handbook. 2nd ed. Nature Publishing Group, New York.

Song MI, Iwata K, Yamada M. 1994.Multisampling analysis using an array of microreactors for an alternating-current field-enhanced latex immunoassay. Anal Chem 66: 778-781.

Tuerk C, Gold L. 1990. Systematic evolution of ligands by exponential enrichment: RNA ligands to bacteriophage T4 DNA polymerase. Science 249: 505-510.

Turner AP. 1997.Immunosensors: the next generation. Nat Biotechnol 15: 421.

Turner APF, Chen B, Piletsky SA. 1999. In vitro diagnostics in diabetes: meeting the challenge. Clin Chem 45: 1596-1601.

Volpe G, Ammid NH, Moscone D, Occhigrossi L, G. Palleschi G. 2006. Development of an immunomagnetic electrochemical sensor for detection of BT-CRY1AB/CRY1AC proteins in Genetically Modified Corn samples. Anal Lett 39 (8): 1599-1609

Wang J. 2000. From DNA biosensors to gene chips. Nucleic Acids Res 28: 3011-6.

Winter G, Griffiths AD, Hawkins RE, Hoogenboom HR. 1994. Making antibodies by phage display technology. Ann Rev Immunol 12: 43355 .

Wolfbeis OS. 2000.Fiber-optic chemical sensors and biosensors. Anal Chem 72: 81R-89R

Yang J, Gao P, Liu YR, Hongmin Ma, Du B, Wei Q. 2015. Label-free photoelectrochemical immunosensor for sensitive detection of Ochratoxin A. Biosens Bioelect 64: 13-18. [Early Publication]

Zacco E, Adrian J, Galve R, Marco MP, Alegret S, Pividori MI. 2007. Electrochemical magneto immunosensing of antibiotic residues in milk. Biosens Bioelect 22 (9-10): 2184-2191.

Zacco E, Galve R, Marco MP, Alegret S, Pividori MI. 2006. Electrochemical biosensing based on universal affinity biocomposite platforms. Biosens Bioelect 21 (7): 1291-1301. 